\title{
Attitudes of consumers on E-waste management in Greece
}

\author{
K. Abeliotis, D. Christodoulou \& K. Lasaridi \\ Harokopio University, Athens, Greece
}

\begin{abstract}
Waste from electric and electronic equipment (WEEE) is the fastest growing waste stream in the European Union. WEEE may cause environmental problems due to its hazardous materials contents. On the other hand, recycling of WEEE is an important issue, not only from the point of waste treatment, but also from the aspect of recovering valuable materials. This paper presents data on WEEE generation and the status of WEEE recycling in Greece, in its current early stage. It also presents the attitudes and behaviour of Greek consumers regarding WEEE management practices. A field survey based on a closed-type questionnaire was conducted. The survey took place in the city of Athens in the first months of 2005. The main results of the study indicate that WEEE generation in Greece will continue to grow and that people are willing to get involved provided that the needed infrastructure is established.
\end{abstract}

Keywords: WEEE, E-waste, Greece, public opinion.

\section{Introduction}

The production of electric and electronic equipment is increasing worldwide. Both technological innovation and market expansion continue to accelerate the replacement of equipment leading to a significant increase of waste electric and electronic equipment (WEEE) [1]. WEEE is recognised as the fastest growing waste stream in the European Union (EU), with estimates of 14-20 kg per person per annum, and it is increasing at about three times higher rate than the average for municipal waste [2]. Currently in the EU-15, WEEE accounts for $8 \%$ of all municipal waste [3]. WEEE consists of a wide range of electronic devices that can be classified into three groups, namely white goods, brown goods and information technology (IT) scrap [4]. 
E-waste contains more than 1,000 different substances, many of which are toxic, such as lead, mercury, arsenic, cadmium, selenium, hexavalent chromium, and flame retardants that create dioxins emissions when burned [3]. WEEE may cause serious environmental problems during the waste management phase if it is not properly pretreated.

On the other hand, recycling of WEEE is an important issue not only from the point of waste treatment but also from the aspect of recovering valuable materials. E-waste contains valuable substances such as gold and copper [3]. For example, early generation PCs used to contain up to $4 \mathrm{~g}$ of gold each; however this has decreased to about $1 \mathrm{~g}$ today [3]. One ton of e-waste contains up to 0.2 tons of copper, which can be sold for about $€ 500$ at the 2004 world price [3]. Recyclable material from WEEE typically consists of ferrous metals $(47 \%)$, plastics $(22 \%)$, glass $(6 \%)$ and non-ferrous metals (4\%) [4]. Well established take-back and recycling systems for WEEE, such as the one in Switzerland, have proven clear environmental advantages, compared to the complete incineration of all WEEE [5].

The European Commission, recognising the need for legislation to address the escalating problem of WEEE, introduced Directive 2002/96/EC on WEEE. The central theme of the Directive is extended producer responsibility and aims to increase, rates of reuse, refurbishment and recycling. The Directive sets a target: by December 31, 2006 at the latest, a minimum rate of separate collection of 4 $\mathrm{kg}$ on average per inhabitant per year of WEEE must be achieved [6]. This target is already met in the UK [2] while in well organised WEEE management systems, such as the one in Switzerland, $11 \mathrm{~kg}$ per capita per year are reported [5]. However, for EU members like Greece, that are starting its WEEE recycling from scratch, this target is very ambitious. The Directive also requires producers to set up systems for recovery and recycling of WEEE, either collectively or individually. It is the responsibility of the producers that the specific recovery and recycling targets are met (see Table 1).

The treatment of the hazardous material as well as its precious metal recovery depends on the collection rate of WEEE. White goods, i.e. household appliances such as refrigerators and cookers, have a high metal content and therefore a high collection rate. For example, the collection rate in the U.K. in 2000 was reported at $90 \%$ [4]. Brown goods, i.e. household electrical entertainment appliances (DVD players, TVs, radios, etc.), easily fit into the municipal solid waste (MSW) collection bins. Therefore, its collection rate in U.K. was reported for 2000 at $50 \%$ [4]. Large household appliances, small household appliances, IT and telecommunication equipment, and consumer equipment account for almost $95 \%$ of the WEEE generated [3].

\section{The situation in Greece}

The electrical and electronic goods trade sector is one of the most active economic sectors in Greece. It is reported that in 2003, 1.2 billion $€$ was spent on electric appliances trade, excluding the part of IT and telecommunications [7]. In 2005, 540,000 TV sets were sold in Greece, 140,000 Hi-Fi systems, 600,000 
DVD players, 180,000 DVD recorders, 270,000 digital photo cameras, 100,000 videocameras, 500,000 PC monitors and 220,000 laptops [7]. The latest data for white appliances are from 2003: 330,000 refrigerators were sold, 30,000-50,000 freezers, 320,000 cookers, 250,000 washing machines and 80,000 dishwashers [7]. In addition 2.8-3.0 million mobile phones were sold in Greece in 2005 [7]. The annual WEEE production in Greece is currently estimated at 170,000 tons. It is projected that, by the end of 2008, it will reach 185,000 tons, which corresponds to $14.4 \mathrm{~kg}$ per capita annually.

Table 1: $\quad$ Targets of 2002/96/EC Directive on WEEE [1].

\begin{tabular}{|c|c|c|}
\hline & $\begin{array}{l}\text { Minimum } \\
\text { recovery } \\
\text { rate } \\
\\
(\%) \\
\end{array}$ & $\begin{array}{l}\text { Minimum rate of } \\
\text { component } \\
\text { material and } \\
\text { substance reuse } \\
\text { and recycling } \\
(\%) \\
\end{array}$ \\
\hline $\begin{array}{l}\text { Large household appliances and } \\
\text { automatic dispensers, by an average } \\
\text { weight per appliance }\end{array}$ & 80 & 75 \\
\hline $\begin{array}{l}\text { IT and telecommunications equipment } \\
\text { and consumer equipment, by weight of } \\
\text { the appliances }\end{array}$ & 75 & 65 \\
\hline $\begin{array}{l}\text { Small household appliances; lighting } \\
\text { equipment; electrical and electronic } \\
\text { tools; toys, leisure and sport } \\
\text { equipment; monitoring and control } \\
\text { instruments, by an average weight per } \\
\text { appliance }\end{array}$ & 70 & 50 \\
\hline $\begin{array}{l}\text { Gas discharge lamps, by weight of the } \\
\text { lamps }\end{array}$ & - & 80 \\
\hline
\end{tabular}

The WEEE Directive was incorporated into the Greek law as the Presidential Decree 117/2004. In order to fulfil the requirements of the aforementioned Directive, a joint venture company has been established, by the major players of electrical and electronic equipment trade in Greece, called "Equipment Recycling S.A." which is responsible for the organisation and the operation of a collective WEEE recovery system. The target of the system is, by 31 December 2006 , coverage of $90 \%$ of Greek households and the collection of at least 44,000 tons annually, which is the national target for Greece. As of today, 400 companies have already joined the collective system and contracts have been signed with 40 municipalities for WEEE collection. The calculation of the recycling charges per unit weight is based on the break-even principle, i.e. the aim of "Equipment Recycling S.A." is to balance its operational costs with the recycling charges and not make a profit out of it. The calculation of the recycling charges is based on the following parameters [8]: 
- The financial viability and the management costs of the system,

- The principle of no interference to the competition among similar products,

- The quantities of WEEE produced per product category,

- The difficulty of collection and disassembly per product category,

- The cost of removing hazardous materials,

- The income from reselling the recovered valuable materials.

The charge for each item of WEEE is presented in Table 2. The classification of WEEE in this table is based on the ordinances of 2002/96/EC Directive. The prices of this catalogue are valid from February 1, 2005. For electrical and electronic equipment sales from 1/7/2004-31/1/2005 there is a single cover charge for all categories at $€ 59.5$ /ton (including VAT).

Table 2: Recycling charge for participation in the WEEE management scheme in Greece [8].

\begin{tabular}{lc}
\hline Product category & $\begin{array}{c}\text { Recycling charge per unit } \\
\text { weight including 19\% VAT } \\
(€ / \text { ton })\end{array}$ \\
\hline Large household appliances & 85.72 \\
Small household appliances & 95.81 \\
IT and telecommunications equipment & 302.55 \\
Consumer equipment & 302.55 \\
Lighting equipment & 148.75 \\
Gas discharge lamps & $0.120($ per piece) \\
Electrical and electronic tools & 121.02 \\
Toys, leisure and sport equipment & 181.52 \\
Medical technology equipment & 59.50 \\
Monitoring and control instruments & 181.52 \\
Automatic dispensers & 90.76 \\
\hline
\end{tabular}

In terms of management practices in Greece, before the enforcement of the WEEE Directive, large white appliances at the end of their life were handled as bulky solid waste. All the municipalities have collection services for bulky items. People leave their large electrical items next to the MSW collection bins and then call the pick-up service. However, for large white electrical goods with high metal content, there is also an informal collection mechanism consisting of individual garbage collectors who pick up the appliances left for collection. These people then sell the collected appliances as metal scrap, without any form of recovering the valuable components. Until the enforcement of the Directive, this informal collection and scrap recycling was the only action taken to divert WEEE from legal or illegal landfilling. This informal mechanism accounts for 
$80 \%$ of the collected WEEE, even after the introduction of the collective system. Small appliances were placed directly to the MSW bin.

Today, the first WEEE recycling facility is operating $60 \mathrm{~km}$ west of Athens with an annual operating capacity of 20,000 tons, i.e. almost half of the required capacity by the WEEE Directive for the whole country. For this reason, a second recycling facility is underway in northern Greece.

In addition, after the appearance in the Greek market of low price eastern Asian appliances, the second hand market of electrical and electronic goods is very limited. Old PCs are given to charities and friends or stored at home while older appliances are given to friends or family members that, for example, study in a different city. This trend was also reported in a recent telephone survey regarding the use of PCs in Greece [9]. Up to the middle of 2004, all WEEE was landfilled in Greece. The only pre-treatment taking place was crashing them in order to create smaller parts and avoid the operational problems at the landfill.

\section{Methodology}

A field survey was conducted in the first three months of 2005 in the city of Athens using a questionnaire, consisting of 18 closed-type questions. The sample size of the survey was 100 persons. SPSS 10 was used for data analysis. The first part of the questionnaire dealt with the gender, age, education level and family income of the sample. The demographics of the sample are presented in Table 3. The sample is, therefore, mainly consisting of young people. However, each person was asked to represent its household.

Table 3: $\quad$ The demographics of the sample.

\begin{tabular}{|c|c|c|c|c|}
\hline $\begin{array}{r}\text { Male } \\
\text { Female }\end{array}$ & $\begin{array}{l}31 \% \\
69 \%\end{array}$ & & & \\
\hline \multicolumn{5}{|l|}{ Age (y) } \\
\hline $18-25$ & & $50 \%$ & & \\
\hline $26-45$ & & $32 \%$ & & \\
\hline $46-65$ & & $16 \%$ & & \\
\hline$>65$ & & $2 \%$ & & \\
\hline \multicolumn{5}{|l|}{ Education } \\
\hline Primary & & & $9 \%$ & \\
\hline Secondary & & & $57 \%$ & \\
\hline University & & & $34 \%$ & \\
\hline \multicolumn{5}{|l|}{ Family Income $(\epsilon)$} \\
\hline$<15,000$ & & & & $39 \%$ \\
\hline $15,001-30,000$ & & & & $42 \%$ \\
\hline$>30,000$ & & & & $19 \%$ \\
\hline
\end{tabular}

In the second part of the questionnaire, questions relating to the specific goals of the survey were included. More specifically, this study aims to: 
- $\quad$ report the way that consumers manage their WEEE,

- $\quad$ estimate the rate of WEEE production,

- $\quad$ examine what people know regarding WEEE management,

- $\quad$ survey the willingness of the people to participate in WEEE recycling.

\section{Key findings}

The first question was "How often do you read the operational instructions of new electric and electronic equipment?" The aim of this question was to identify if people realise that WEEE has to be handled apart from the rest of MSW. This piece of information is included in the instruction manual of each appliance by the use of a certain logotype. $60 \%$ replied that they always read the manual, $36 \%$ replied sometimes while $4 \%$ never read their manual.

The next question was "How do you handle the large white appliances (refrigerators, washing machines, etc.) at the end of their life?" $56 \%$ replied that they put it on the road, next to the MSW collection bin. $21 \%$ replied that they call the local municipality service for bulky waste. The rest $(23 \%)$ replied that they handled their large white goods differently, meaning that they call on purpose a garbage collector, or they keep them at home. Even though large white goods make up the majority of WEEE by weight, small and medium sized items are the vast majority by number [2]. Therefore, it seems reasonable to expect different management practices from the people regarding small appliances. In the question "How do you handle the small appliances at the end of their life?" $82 \%$ replied that they trash it alongside the rest of MSW.

The next set of questions aimed at identifying the rate of WEEE generation. $78 \%$ of the respondents replied that they bought at least one electrical or electronic appliance during the past year. From the 78 buyers of the sample, $60.3 \%$ bought an IT or telecommunications appliance, $42.3 \%$ bought an entertainment appliance, $35.9 \%$ bought a small household appliance while $23.1 \%$ bought a large white appliance.

The next question, addressed to the buyers of at least one appliance, was "What happened to the respective old appliance?" In this question, 39\% replied that they still own the old appliance and have stored in their home, $22 \%$ claimed that they didn't have a similar appliance or that they bought it for the needs of a new household, $21 \%$ replied that they throw it away in the MSW bin, 14\% gave it as a gift, while only $4 \%$ gave it to an individual collector for scrap recovery. In order to have a better view on the fate of appliances at the end of their life, the appliances that were bought for the very first time are taken out of the calculations. Breaking down the remaining replies into the four major appliances categories, Figure 1 is generated. From there it is evident that old large appliances are more likely $(46.2 \%)$ to be disposed off or given to a third party $(30.8 \%)$. For old small appliances it is easier to keep them at home $(42.9 \%)$ or again give it to a third party $(28.6 \%)$. Old entertainment appliances are mainly kept at home $(53.6 \%)$ or disposed off $(28.6 \%)$. Old IT and telecommunications devices are kept at home $(62.2 \%)$ or given to a third party $(21.6 \%)$. 


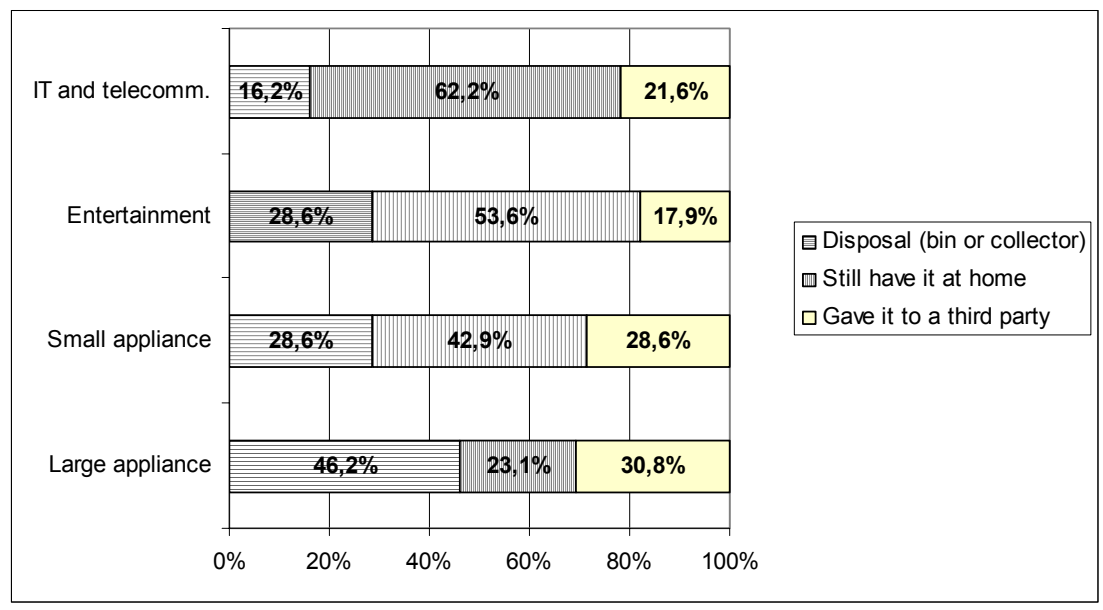

Figure 1: Old appliance management per appliance category.

The following question was "What is the single main reason for buying a new electric or electronic device?" $48 \%$ replied that they buy a new appliance when the old appliance is broken, $40 \%$ replied that they buy a new appliance in order to replace it with a technologically advanced one, while $12 \%$ replied that they buy a new appliance when they don't have a similar old one. The next question was "Identify the single most important criterion when buying a new electrical or electronic appliance?" $67 \%$ replied to be technologically advanced, $14 \%$ replied to have lower price, $18 \%$ replied to be more energy efficient or environmentally friendly while only $1 \%$ replied that they look for better appearance. Breaking down the replies in this question into the four appliances categories, Figure 2 is generated. It is evident that the main reason for buying a new appliance of any kind is to be technologically advanced. For IT and telecommunication devices this statement is also confirmed by the $\chi^{2}$ independence test $\left(\chi^{2}=14.094 ; \mathrm{p}=0.001\right)$. For the large and small household appliances category, energy efficient and environmentally friendly appliances are preferred by more than $20 \%$ of the respondents while low price comes into play only for small appliances.

The next question was "Did you buy a second-hand electric or electronic appliance at least once in your life?" Only $14 \%$ of the respondents gave a positive answer to this question. Out of these 14 people, 5 bought a used large appliance, 8 bought an IT or telecommunications appliance (personal computer or mobile phone) while 1 person bought both a large appliance and a telecommunications device.

The final set of questions aimed at identifying which are the preferences of the sample regarding issues relating to the collection of WEEE. The first question in this set was "Are you willing to pay a fee when you buy a new appliance which will be refunded at the end of its life?" 54\% replied positively, $14 \%$ replied negatively while the rest (34\%) replied "maybe". In the question 
"Which is the most preferable way for you to get rid of a large white appliance?" $57 \%$ of the respondents replied that the most preferable way for them is the retailer from whom they buy the new to collect the old one. $38 \%$ replied that they prefer to put the old appliance next to the MSW bin so that the municipality can pick them up while 5\% asked for a different form of management. The next question was "What is the strongest motive for you to take the old small appliances in pre-specified collection centre?" $36 \%$ replied that a refundable amount of money would be the strongest motive, $36 \%$ that more information on the adverse effects of WEEE on the environment and human health would be the strongest reason, $17 \%$ replied that strong law enforcement would be the strongest motive while $11 \%$ replied that there is no strong enough motive for them to take their old WEEE to a collection centre.

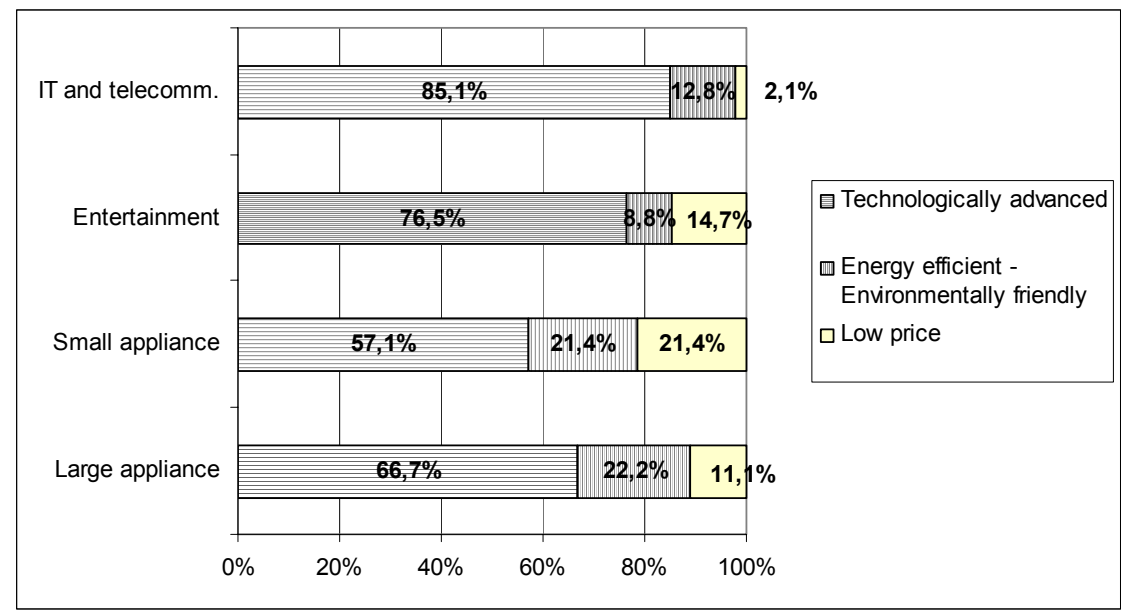

Figure 2: $\quad$ Main reason for buying a new appliance per appliance category.

\section{Discussion}

Prior to the enforcement of the WEEE Directive by the EU, the dominant management practice in Greece was landfilling. Greece is currently building the necessary infrastructure for dealing with its WEEE. The necessary legislative background is already set, allowing the establishment of the first collective WEEE recovery system. In addition to the collective system, there are three more collection ways for domestic WEEE: the infrastructure of the municipalities, the retailers that are required to receive the old appliances on a one to one basis, and the individual collectors. In all four alternatives, the participation of the public is of paramount importance. In terms of WEEE recycling, a single facility operates in Greece, capable of dealing with half of the WEEE amount required by the Directive. Therefore, in order to meet the challenge of the EU Directive, Greece has to speed up. 
The aim of this paper was to present the current status of WEEE management in Greece and to outline, by means of a questionnaire, the opinion and practices of people living in the area of Athens regarding WEEE management. The sample size of 100 persons is small and can only allow for the identification of some trends. From the analysis of the responses to the questionnaires the following trends are identified:

The majority of the people read the instruction manual from the appliances that they buy. This is important because in the manuals it is clearly stated that WEEE must be managed differently and not along with the rest of the MSW.

Since small electric and electronic appliances fit easily in the MSW bin, people tend to get rid of them more easily. Large appliances, due to their size, have to be handled differently. Therefore, for the success of any small appliances recovery program it is essential that this is easily accessible by the public. For large white appliances the easiest way, for the consumers, is to have them picked up by the retailers that bring home the new appliance.

The present survey reveals that consumers in Greece tend to keep home the majority of old electric and electronic appliances, with the exception of large appliances. This is also reported by other authors [10] in a similar survey of 126 households in the urban area of Thessaloniki (see Table 4). This means that the useful life of each appliance is extended; however, eventually, all appliances end up as WEEE.

Table 4: $\quad$ Fate of old appliances in Greece per appliance category.

\begin{tabular}{|l|lc|cc|cc|}
\hline $\begin{array}{l}\text { Appliance } \\
\text { category }\end{array}$ & \multicolumn{2}{|c|}{$\begin{array}{c}\text { \% disposal } \\
\text { (landfill\&collection) }\end{array}$} & \multicolumn{2}{|c|}{$\begin{array}{c}\text { \% given to } \\
\text { third party }\end{array}$} & \multicolumn{2}{|c|}{$\begin{array}{c}\text { \% stored at } \\
\text { home }\end{array}$} \\
\hline & This study $[10]$ & $\begin{array}{l}\text { This } \\
\text { study }\end{array}$ & $\begin{array}{l}\text { This } \\
\text { study }\end{array}$ & {$[10]$} \\
\hline Large & 46.2 & 50 & 30.8 & 30 & 23.1 & 20 \\
\hline Small & 28.6 & 80 & 28.6 & - & 42.9 & - \\
\hline Entertainment & 28.6 & 35 & 17.9 & - & 53.6 & - \\
\hline IT and telecom. & 16.2 & 20 & 21.6 & 40 & 62.2 & 40 \\
\hline
\end{tabular}

The main reason that people buy new appliances is the technological advancements. This is especially true for IT and telecommunications appliances. Moreover, the trade of second hand electrical and electronic appliances in Greece is very limited. Both these results indicate that WEEE generation will continue to grow in Greece.

In terms of people's involvement in the recovery process, people think than a refundable amount of money and more information are the strongest motives for getting involved.

Closing this paper, it is important to state that the involvement of consumers is of paramount importance in the WEEE recovery process, provided that the infrastructure is there. In order to get people involved, more information and education is needed regarding the adverse environmental impacts that WEEE 
may cause. Information sources may be the municipalities, the collective system, the retailers of the electrical and electronics goods, and the mass media.

\section{Acknowledgement}

This research was supported in part by Pythagoras II programme (MIS: 97456, subproject 1) co-funded by the European Social Fund (75\%) and National Resources (25\%).

\section{References}

[1] Cui, J. \& Forssberg, E., Mechanical recycling of waste electric and electronic equipment: a review. Journal of Hazardous Materials, B99, pp. 243-263, 2003.

[2] Darby, L. \& Obara, L., Household recycling behaviour and attitudes towards the disposal of small electrical and electronic equipment. Resources, Conservation and Recycling, 44, pp. 17-35, 2005.

[3] Widmer, R., Oswald-Krapf, H., Sinha-Khetriwal, D., Schnellmann, M., \& Böni, H., Global perspectives on e-waste. Environmental Impact Assessment Review, 25, pp. 436-458, 2005.

[4] Mohabuth, N., \& Miles, N., The recovery of recyclable materials from Waste Electrical and Electronic Equipment (WEEE) by using vertical vibration separation. Resources, Conservation and Recycling, 45, pp. 60-69, 2005.

[5] Hischier, R., Wager, P., \& Gauglhofer, J., Does WEEE recycling make sense from an environmental perspective? The environmental impacts of the Swiss take-back and recycling systems for waste electrical and electronic equipment (WEEE), Environmental Impact Assessment Review, 25, pp. 529-539, 2005

[6] Directive 2002/96/EC of the European Parliament and of the Council of 27 January 2003 on waste electrical and electronic equipment. Official Journal L037:0024-39 [13/02/2003], europa.eu.int/eur-lex/en/

[7] STATBANK, www.statbank.gr/sbstudies.asp

[8] Equipment Recycling S.A., www.electrocycle.gr

[9] Valta, A.A., Menegaki, M.E. \& Kalampakos, D.C., Electronic Waste Management in Greece: Are people ready to get involved in the process? Proc. of the 9th International Conference on Environmental Science and Technology, ed. T.D. Lekkas, Rhodes, Greece, pp. A1560-A1565, 2005.

[10] Karagiannidis, A., Papadopoulos, A., Moussiopoulos, N., Perkoulidis, G., Tsatsarelis, Th., \& Michalopoulos, A., Characteristics of wastes from electric and electronic equipment in Greece: Results of a field survey. Proc. of the 8th Int. Conf. on Environmental Science and Technology, ed. T.D. Lekkas, Lemnos, Greece, pp. 353-360, 2003. 